\title{
COVID 19: A Strange Worldwide Pandemic
}

\author{
Dr.SnehaLodhi \\ Intern, Dept. of Community Medicine, Jawaharlal Nehru Medical College, DattaMeghe Institute of Medical \\ Sciences (Deemed to be University), Sawangi (Meghe), Wardha-442001, Maharashtra, \\ Email Id: lodhisneha29@gmail.com \\ Review Article \\ Conflict of Interest: None
}

\begin{abstract}
:
Corona virus disease (COVID -19) is a severe acute respiratory syndrome which cause respiratory tract illness. The pandemic caused by virus originated in Wuhan. Later declared as a pandemic by WHO. It causes symptom like common cold, fever, body ache, cough and loss of taste sensation which are commonly seen in most of the patient. Older and one with comorbidity are at high risk to get infected. The average time period from exposure to symptoms is 5 days. Many asymptotic cases where reported which shows no symptoms but show viral load on RT-PCR. Patients are considered covid-19 positive based on clinical features \& radiological findings. On chest X-ray it shows ground-glass opacity. More than 75 percent of patients hospitalized require supplemental oxygen. Treatment for individual with COVID -19 include best practice for supportive management of acute hypoxic respiratory failure. Immediate hospitalization of positive patient if spo 2 drops below 95 percent . Diagnosis is made by detection of SARS cov-2 via reverse transcription polymerase chain reaction testing, although false positive result may occur in up to 20 to $60 \%$ patients. Suspected cases are quarantine for 14 days. Preventive measures include hand washing, social distancing etc. Recently COVISHEILD \& COVAXIN is approved for emergency use. Reaction of vaccination include fever ,body ache, swelling at local site, pain, malaise, joint pains.
\end{abstract}

Keywords : SARS cov-2, ground glass opacity, quarantine, vaccine .

\section{INTRODUCTION :}

In December 2019, a series of acute atypical respiratory tract occurred in Wuhan, China. This infection widely spread from Wuhan to other areas. The virus which is responsible for infection was later recognised as novel Coronavirus. The novel Coronavirus was named as acute respiratory tract syndrome (SARSCoV-2).It was considered that this infection was spread from sea-market of Hubei China but later discovered that it spread through droplet or aerosol. After the rapid spread of virus in different part of world ,World Health Organisation (WHO) declared it as a Pandemic. Initially during start of corona infection it presents in a similar fashion like common cold .People of older age and one with comorbidities are at higher risk of contracting infection due to their weekend immune system. Most patient of younger age with mild symptom donot need medical attention ,all they need to do is self-

isolate themselves so as to brake chain of transmission .

History:- Human coronavirus was first identified in 1965. It caused common cold. It was isolated from case of common cold by inoculating organ culture of human embryonic trachea with Nasopharyngeal washing. In November 2002 Guangdong province in south china. Experienced breakout of sever acute respiratory syndrome (SARS) with many death .In 2003 the world outside knew about it. At the end of 2019 novel coronavirus was originated in Wuhan, a city of china. It is a zoonotic disease from civet ,cats ,bats .Later recognised as pandemic on 11 march 2020 due to worldwide spread of virus.

\section{MORPHOLOGY:-}

Coronavirus is a group of spherical or pleomorphic enveloped RNA carrying 
petal or club shaped peplomer on the surface (1). The size of coronavirus is in range of 26 to 32 kilobases. It has fringe of surface projection surround it, resemble the solar corona.

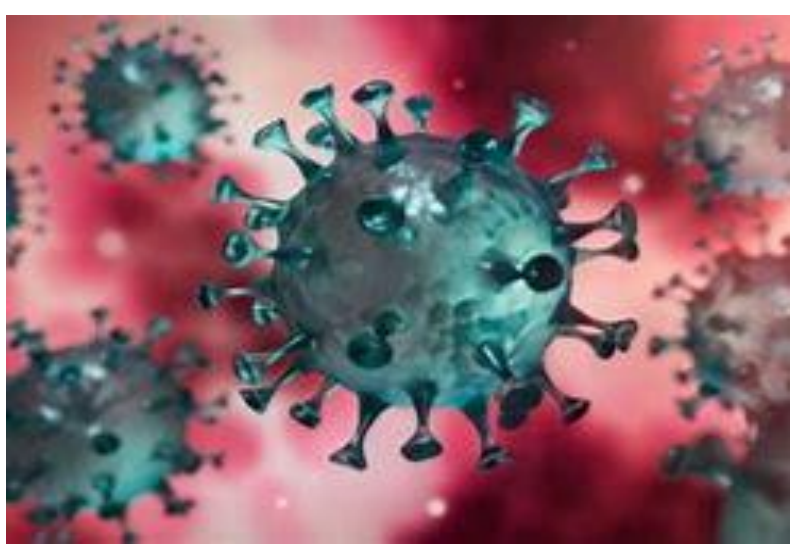

\section{CLASSIFICATION OF VIRUS (2) \\ Order : NIDOVIRUS \\ Family : CORONAVIRIDAE \\ Genera: Alphacoronavirus \\ Betacoronavirus \\ Gammacoronavirus \\ Deltacoronavirus \\ Lineage of Beta COV : SARS-COV MHV \\ MERS - COV}

Epidemiology : On December 2019 WHO reports viral pneumonia case of unknown cause in Wuhan (3). On 30 January WHO declared it as outbreak with 7818 case globally affecting 19 countries). In India till November 22 91,25,990 Positive cases are seen with 45,882 new infection. Maharashtra reports 17,84,361 cases include 4153 new covid cases on Monday. Route of Transmission :Spread of Coronavirus occur in subsequent ways:

(1)Coughing and sneezing without covering mouth can cause aerosol spread.

(2)Touching and shaking hands that is contact route.

(3)Faeco-oral transmission.

(4)Virus remain viable on cupboard, copper and stainless steel upto 3 days that is Surface Transmission.
No cases of transmission from mother to fetus during pregnancy and no evidence of virus in breast milk. (4)(5)

Duration of transmission:

Symptomatic people are most infectious, some can get infected 2 days before the appearances of symptoms.

Moderate case remain infectious for estimated period of 7-12 days and an average 2 weeks in severe cases. June2020 review shows that 40-45\% infected person are asymptomatic.

Upper respiratory specimen shows viral RNA load more soon after symptoms onset as compared to later in the illness (6). And 1-3 days before symptoms appear SARS COV -2 RNA can be visualised and the highest viral load observed around the day of symptom onset by RT-PCR technique followed by gradual decrease of viral load over time(7)

RT-PCR positivity duration appear to be 1-2 weeks for individual without any symptom and individual with mild moderate symptoms it appear upto 3 weeks or more (8) and much longer duration of positivity for severe cases. Studies show the existence of deadly SARS-COV 2 through viral culture of patients sample (9) Incubation period:

Latent period that is duration between exposure and symptom of Covid- 19 belief to be 14 days following exposure, with most cases appeared approximately four to five days after exposure (10-11) Confirmed infections with an estimation of disease severity (12)

[1]Mild disease (no or mild pneumonia )81 percent

[2] Severe disease (example with dyspnea ,hypoxia or $>50$ percent lung involvement on imaging within 24-48 hours )-14 percent

[3]Critical disease (example respiratory failure, shock, or multiorgandysfunction )5 percent

Clinical Manifestations :

Most common symptoms that are seen in patients are: 
[1]Fever-85 percent (only 45 percent febrile on presentation)

[2]Dry Cough-50-85 percent

[3]Tiredness

Less common symptoms seen are followings:

Aches and pain

Sore throat

Diarrhoea

Conjunctivitis

Headache

Loss of taste sensation

Gastrointestinal symptoms $\{10$ percent $\}$

Severe symptoms experienced by patients are:

[1] Breathlesness

[2]Chest pain or pressure

[3] Loss of speech or movement

[4]Coughing up blood

[5]Kidney failure

[6]High fever

In such cases, the development can lead to severe pneumonia, sepsis, shock ,Acute respiratory distress syndrome $\{$ ARDS $\}$ and death. Some of infected individual will not show any clinical symptoms or remain asymptomatic but test result can turned out to be positive that confirmed infections.

\section{Data about Asymptomatic covid infected patient:}

Asymptomatic patients are those which carry viral load but do not show any covid symptoms. It has been observed that most of the asymptomatic covid -19 patients are healthy young and healthy children. Virus can remain viable in our body for upto 70 days it signify that virus can be spread within this duration.

According to early research signify that rate of asymptomatic infection could be as high as 81 percent but meta-analysis published last month which include 21,708 individual ,the rate of asymptomatic observed are 17 percent. These people play a significant role in public health risk as they are more likely to be out in the community than isolated at home.
Clinical abnormalities can be seen in patient without symptom. The patient without symptom when underwent chest computed tomography $\{\mathrm{CT}\}$, almost 50 percent of them shows typical groundglass abnormalities while 20 percent showed atypical imaging abnormalities.

\section{Blood clots appearing in COVID-19 patients:}

Discovered gel like clumps in blood of Covid patients that causes severe fatal problem such as Heart attack and Stroke. In some Covid patient autopsies found tiny blood clots throughout lungs. The clots seen may be result of an overactive immune system which causes imbalance in "clotting factor" result in clotting. High risk category (13)

Individual who come under high risk category need to take extra precaution and need to take immediate medical attention as soon as they develop covidsymptoms.

Following are the individual who came under this category:

- Over 60 years of age

- Heart ,lung, kidney disease

- Immune dysfunction

- Had solid organ or marrow transplant

- Individual who are on steroid

- Patient on chemotherapy

- Patients with uncontrolled diabetes.

- Hypertension

\section{Laboratory findings :}

In individual with clinical symptoms of covid-19, laboratory finding can be seen :
A.Lymphocytopenia
B.Thrombocytopenia
C.Elevated liver transaminase
D.Elevated C-reactive protein
E.Erythrocyte sedimentation rate
F.Elevated serum lactate dehydrogenase
G.Decreased or normal albumin

H.In myocardial injury elevated serum troponin $-\mathrm{T}$ can be seen 
HISTOPATHOLOGICAL CHANGES : Changes which are observed in lungs of covid -19 patients

1.Hyaline membrane formation

2.Desquamation of Pneumocytes

3.Fibrin deposits in lungs

4.Inflammation with mononuclear cells

5.Diffuse alveolar damage

Following tests are done in covid 19 infected individual

[1] VIRAL TESTING:

RT-PCR is done for qualitative detection of nucleic acid of SARS CoV-2. Swab are usually taken form nose ,nasopharyngeal , oropharyngeal, sputum or lower respiratory tract aspirate.(14)

[2] SEROLOGY

It is particularly useful when :

- Viral test is not possible

- Patients with late disease complication

- In individual in whom viral shedding decreased so RT PCR is giving false result.

Not useful in the diagnosis of present infection but can assess previous exposure to virus.

SARS COV-2 antibodies such as IgM and IgG detected in serum, plasma or in whole blood..

[3] RAPID ANTIGEN TEST:

Rapid antigen test is a monoclonal antibody test against SARS-COV 2 nucleocapsid protein. which is abnormally seen in diseased individual. According to report sensitivity is 84.1 percent and specificity of 98.5 percent
4]
CHEST
COMPUTED

TOMOGRAPHIC SCAN :

According to earlier studies during initial breakout in china it is concluded that individual are considered positive on the basis of clinical presentation, presence of pneumonia and chest tomographic scan. The author proposed that clinical features and chest tomographic scan are better tool for covid -19(15). Study reveal that it shows small patchy air space opacities with ground glass opacity in lung parenchyma.

\section{CO-RADS SCORE}

LEVEL TO SUSPECT INFECTION BY

COVID-19

\section{CT FINDING}

CO-RADS 1 No Normal or noninfectious abnormalities

CO-RADS 2 Low Abnormalities

consistent with infection other than COVID 19

CO-RADS 3 Indeterminate Unclear whether COVID -19 is present

CO-RADS 4 High Abnormalities

suspicious COVID -19

CO-RADS 5 Very high Typical

COVID - 19

CO-RADS 6 PCR

\section{Complications :}

According to study reveal men are more likely to develop more serious complication as compared to female (16)

The complication noticed in patient with SARS-COV -2 include:

[1]Laryngitis and laryngeal oedema

[2]Coagulopathy mainly disseminated intravascular coagulation, venous thromboembolism, elevated D-dimer, prolong prothrombin time.

[3]Panton -Valentine leukocidin secreting Staphylococcus aureus infection cause Necrotizing pneumonia which is fatal.

[4]sepsis ,multiple organ failure, septic shock.

[5]Massive pulmonary embolism complicated by acute right sided heart failure.

[6]Approximately 5 percent patient admit in intensive care unit because they undergo fatal complication by acute respiratory syndrome (17).

$\square$ [7]Around 30 percent patients require intensive mechanical ventilation.

Timeline of COVID-19 (lab wise):

$\square$ Day 0: infected

$\square$ Upto day 5: Onset of symptom 
$\square$ Day 7 :IgM positive (D7-D21)

Day $14:$ IgG positive

$\square$ Day 1-28 : SARS CoV2 RNA and antigens disappear

$\square$ Day $21:$ :gM disappear

$\checkmark$ Day 28: SARS CoV 2 RNA and antigens disappear

$\square$ D0D5 : ASYMPTOMATIC PHASE

$\checkmark$ D0D7 : WINDOW PERIOD (ONLY PCR IS POSITIVE )

$\checkmark$ D14D21 : DECLINE PHASE ( STILL INFECTIVE)

\section{$\square$ D21-28 : CONVALESCENCE PHASE \\ THERAPEUTIC:}

Managed with supportive care which include:

$\square$ Fluid therapy

$\square$ Oxygen support

$\checkmark$ Supporting other affeced vital organs

CDC recommended suspected case should wear simple face mask

Drug recommended in treatment are:

Antibody - Marilimumab (18)

Antiviral- Antiviral drugs that have previously developed against MERS COv and SARS COv. It stops the multiplication of virus so it is beneficial if given within 9 days.

Favipravir(19)

Remdesivir (20)

Ribavirin (21)

Antiparasitic :Hydroxychloroquine

Antibiotics :Oritavancin

Dalbavancin (22)

Azithromycin(23)

Steroids : Oral Prednisolone $20 \mathrm{mg}$ or dexamethasone $4 \mathrm{mg}$ per day for 5-7 days will work if mild symptoms are present. It also prevent long term fibrosis. It should be given for 2 to 3 weeks if hypoxia is experienced in patient. Dexamethasone is pro diabetic so it is essential to monitor blood sugar level as long patient is on steroid .

Anticoagulation: Injection Clexane $0.5 \mathrm{mg}$ subcutaneous BD if D-dimer is normal, should be given $1 \mathrm{mg}$ subcutaneous if $\mathrm{D}$ - dimer is elevated. Oral anticoagulant like tab Rivoroxaban $10 \mathrm{mg}$ OD for 4 weeks can be prescribed after 5 days. If individual is hypoxic both steroids and anticoagulant are manadatory.

Immunological: Drugs with immune modulating effect are

Type 1 interferon

Anti-IL 6 agent [Tocilizimab](24) : If given don't manifest fever or raised as a marker of infection.

Australian GPs released IVERMECTIN TRIPLE therapy (Ivermectin + Doxycycline +Zinc) of COVID-19 for infected elderly and frontline workers which can be prescribed to COVID -19 positive individual .This can be legally. Drugs are cheap, FDA and TGA approved and have outstanding profile .

International data reports an almost 100 percent cure rate and symptoms improvement within 4-6 days.

Molnupiravir an experimental drug discovered by research team led by $\mathrm{Dr}$ Richard Plemper that is orally active. It can hamper the spread of SARS-COV -2 within 24 hours. Now it is advanced phase 2 and 3 clinical trial against infection.

\section{Treatment usually prescribed to Covid positive patient :}

Flaviflu 9 tablets BD X 1 day

Followed by 4 tablets BD x 7 to 14 days

Doxycycline 1BD X 5days

Pantaprazole $\mathrm{x} 5$ days

Ivermectin 12 BD X 5days

Vitamin C $500 \mathrm{Mg}$ BD X15 days

Zinc tablet $50 \mathrm{mg}$ BD X 15 days

Vitamin D once a week.

Record po2 and temperature three times daily

VACCINE: Recently Covishield ,Coxavin is approved for emergency use on $3 \mathrm{rd}$ January 2021 which will firstly provided to frontline and healthcare worker and to the individual above 50 years of age and other with comorbidity. It would be given in 2 doses 28days apart. 


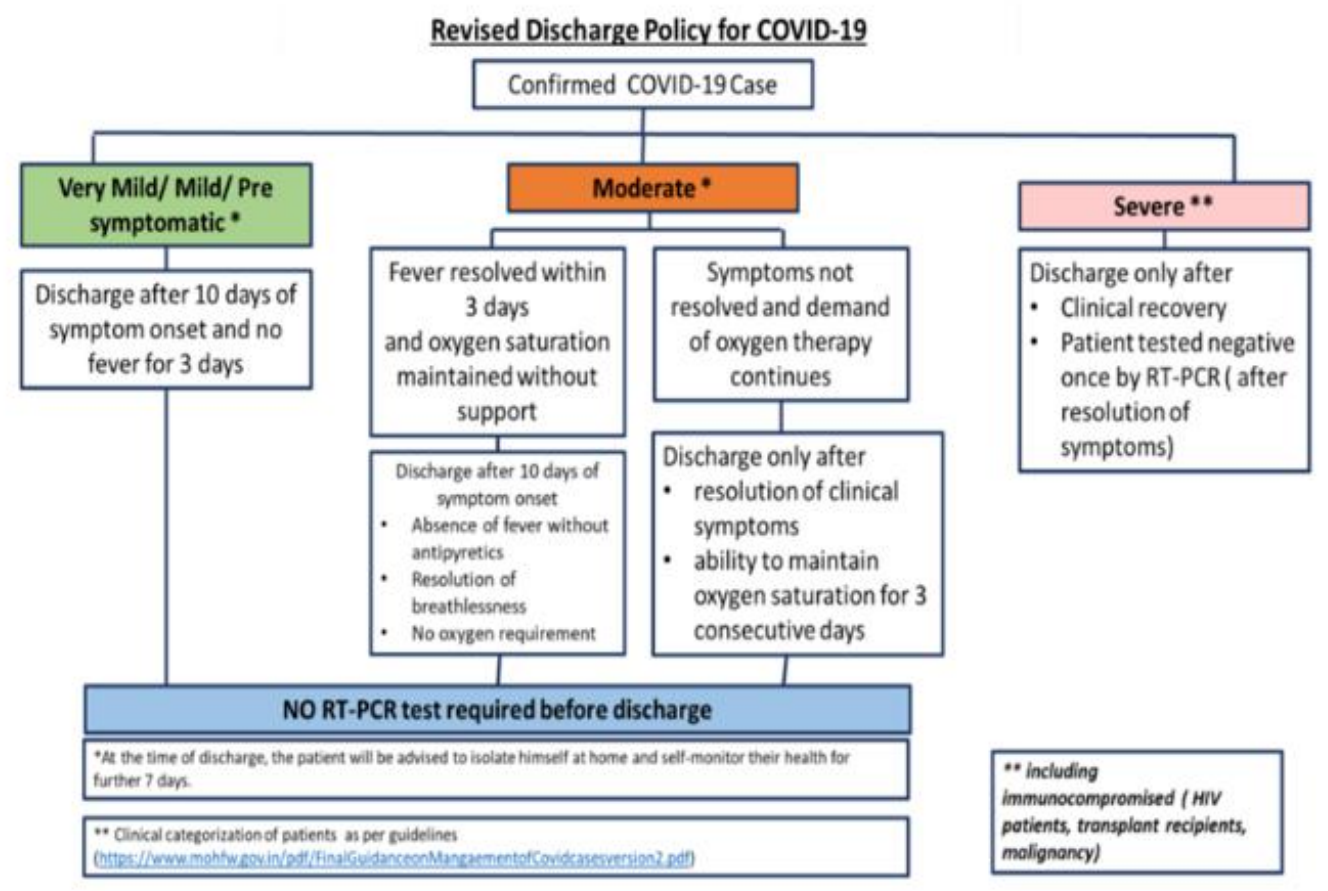

\section{PREVENTIVE MEASURE (25)}

1.Handwashing for minimum 20 seconds with an alcohol based sanitizer and respiratory hygiene

2.Covering one's mouth while coughing

3.Social distance and wearing masks .

4.Quarantine

5.Monitoring and self -isolation for suspected individual.

6.Medical masks

7.Screening of travellers

8. Wear personal protective equipment.

9.Screening : Who have been exposed to suspected patients should be advised to home quarantine for 14 days from last day of possible contact and seek medical attention if they develop symptoms.
10.Social distancing : Maintaining 1-2 meters (approximately 3-6 feet ) distance.

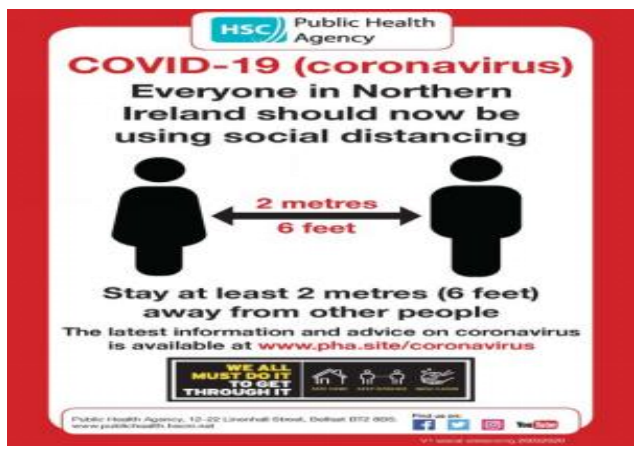

DIFFERNTIAL DIAGNOSIS:

\begin{tabular}{|l|l|l|l|}
\hline & COVID -19 & INFLUENZA & COMMON COLD \\
\hline Incubation period & $2-14$ DAYS & $1-4$ DAYS & $\begin{array}{l}\text { LESS THAN 3 } \\
\text { DAYS }\end{array}$ \\
\hline Onset & gradual & sudden & Sudden \\
\hline Dyspnea & common & rare & Never \\
\hline Fever & Very common & common & Rare \\
\hline Sore throat & sometime & sometime & Rare \\
\hline
\end{tabular}

COVID -19 IMPACT ON : 1]DEVELOPMENT :
COVID -19 as it originated from developed city such as china so it signify 
that developed countries and rich population there also are not immune to the breakout disease such as covid-19 which is highly contagious .It was believed that poverty and underdevelopment lead to infectious disease but it have turned wrong as developed countries has undergone through this deadly virus. Development all around such as building dam ,highly dense populations, migration of people, deforestation in some way have brought ecological changes, global warming also predispose to spread infectious disease throughtout world. This all have lowered down the economy of countries all over the world which in some way affected every individual. During lockdown many companies were closed and in some there was manufacturing of essential goods were slowed so it disrupted the marketing and chain of products which lead to losses in national and international level.

\section{2]HUMAN BEING:}

COVID-19 affected people a lot as many have lost their job after pandemic, the effect of pandemic badly affected poor family specially daily wage earner who do work on daily basis to get money they suffered a lot during lockdown as they can't go out for their work and earn something to eat food of one time. Migrant worker , companies employers, even businessman all have undergone losses during pandemic which affected the economy of country. It also caused mental trauma to everyone as all have suffered losses , have to maintain social distancing with their own family members ,as people were stuck away from home, fear to go out in hospital even if they are ill and tried home remedies to get better. During lockdown even now people freak out to go to hospital even if suffer from normal cold, cough because of fear of coming positive and quarantine, this has set fear in mind of people. Social health worker who are the first liner to provide immense service to people without fear, many of them lost their life while providing health service to people.

\section{IMPACT ON CHILDREN :}

Due to lockdown during pandemic schools, colleges got closed to avoid crowding, setting children under one roof and to prevent spread of disease. To prevent academic loss, online classes came into play which had prons and cons . Online classes cons point that children don't get that student friendly environment like in class, their concentration power ,sitting ability at one place got hampered. It impose them to psychosocial burden than the physical suffering caused by virus .Due to school closure, lack of outdoor activity disrupted their usual lifestyle and promote monotony, impatience, annoyance and various neuropsychiatric problem. There is rise of child abuse, domestic violence from before. Restriction from outdoor activity children are more got involved in online gaming .

A number of related studies were reported from this region (25-27). Useful studies on prevention of spread of infection were reported (28-31). Khatodet. al.(32) and Dhole et. al. (33) discussed on disinfection in dentistry. Late et. al. elaborated on protocol for handling and disposal of the dead bodies in Covid-19 (34).Studies on therapeutic options for Covid were reported by Recheet. al. [35] and Thakareet. al [36]. Darwateet. al and Deogade et. al .reportedAyurvedic remedies[37,38]. Jameelet. al reported on drugs and therapies for children [39]. Joseph et. al. described on palliative care of Covid patients [40]. Afaque reported about treatment of diabetes in patients affected by covid-19[41]. Some interesting studies were reported by Agrawal et. al [42], Dhole et. al.[43] and Gulhane et. al. [44].

\section{CONCLUSION:}

This is a review article on coronavirus in which I have dealt with its basic 
morphology, epidemiology, clinical feature, investigation, treatment. It primarily spread by droplet spread from person to person and cause respiratory tract infection. Feature which are commonly seen are cough, cold, fever, headache, loss of taste and smell. It also cause dyspnea, ARDS and multi organ failure in severe cases. On CT scan it shows ground-glass opacities. Drugs like hydroxychloroquine, ivermectin, steroid are used. After long trial some vaccines like covishield, sinopharm, coxavin are approved. Preventive measure such as social distancing, proper hand washing, using mask need to be follow for better control .

\section{REFERENCES:}

[1] Rezabakhsh A, Ala A, Khodaei SH. Novel Coronavirus (COVID -19): A New Emerging Pandemic Threat . Journal of Research in Clinical Medicine .2020;8(1):5.

[2] deGrootRJ,BakerSC,BaricR,Enjuane sL,GorbalenyaAE,HolmesKV,Perlm anS,PoonL,RottierPJ,TalbotPJ,WooP C,ZiebuhrJ(2011)."FamilyCoronaviri dae".InKingAM,LefkowitzE,Adams MJ,CarstensEB,InternationalCommit teeonTaxonomyofViruses, Internation alUnionofMicrobiologicalSocieties. VirologyDivision(eds.).NinthReporto ftheInternationalCommitteeonTaxon omyofViruses.Oxford:Elsevier1.pp.8 06-28.ISBN978-0-12-384684-6

[3] World Health Organisation DirectorGeneral's opening remarks at the media briefing on COVID-19 -24 February 2020 https://www.who.int/dg/speeches/det ail/who-director-general-s-openingremark-at-the-media-breifing-oncovid-19-24-february-2020

[4] Zhu H, Wang L, Fang C, et al. Clinical analysis of 10 neonate born to mothers with 2019-nCoV pneumonia.
Pediatr.2020;9:51-60. Doi:10.21037/tp.2020.02.06

[5] Chen Y, Peng H, Wang L ,et al. Infants born to mothers with new coronavirus Front Pediatr.2020;8:15.doi:10.3389/fped.2020.0010

[6] "Novel Coronavirus : Information for clinician". Australian Government Department of Health.3 April 2020.

[7] Pan Y ,Zhang D, Yang P, Poon LLM, Wang Q. Viral load of SARSCoV-2 in clinical samples .Lancet infectDIS.2020;20(4):411-2

[8] Qi L, Yang Y ,Jiang D, Tu C, Wan L, Chen X, et al. Factor associated with duration of viral shedding in adults with COVID-19 outside of Wuhan, China :A retrospective cohort study. Int J InfectDis.2020;10.1016/j.ijid.2020.0 5.045 .

[9] Criteria for releasing COVID-19 Patients from isolation Geneva: World Health Organisation;2020( available at http://www.who.int/newsroom/commentaries/detail/criteriafor -releasing-covid-19-patient -from isolation )

[10] GuanWJ,NiZY,HuY,etal.ClinicalCha racteristicsofCoronavirusDisease201 9inChina.NEnglJMed2020.

[11] ChanJF,YuanS,KokKH,etal.Afamilia lclusterofpneumoniaassociatedwithth e2019novelcoronavirusindicatingpers ontopersontransmission:astudyofafa milycluster.Lancet2020;395:514

12)WuZ,McGooganJM.Characteristi csofandImportantLessonsFromtheCo ronavirusDisease2019(COVID19)Ou tbreakingChina:SummaryofaReporto f72314CasesFromtheChineseCenterf orDiseaseControlandPrevention.JAM A2020.

[12] BurkeeR.M, MidgleyC.M ,DratchA.etal . Active Monitoring Of Person Exposed To Patients With Confirmed COVID-19-United States, January- 
February2020.MMWRMorbMortal WklyRep2020;69:245

[13] K.H. Hong, S.W.Lee, T.S. Kim, H.J.Huh,

J.Lee,S.Y.Kim,etal.Guidelines for Laboratory diagnosis 2019 in Korea. Ann Lab Med,40 (5) (2020 Sep)10.3343/alm-2020.40.5.351.

[14] X.Chen, Y.Tang, Y. Mo, S. Li, D.Lin, Z. Yang, et al. A diagnostic for coronavirus disease 2019(covid19) bases on radiological semantic and clinical features: a multicentre study .EurRadiol(2020 apr16),pp. 110, 10.1007/s00330-020-06829-2

[15] D.E.L. Promislow A geroscience perspective on COVID -19 mortality J Gerontol A BiolSci Med Sci (2020)

[16] S. Kluge, U. Janssens, T. Welte, S. We ber-Carstens, G. Marx, C. Karagiannidis German recommended for critically ill patients with COVID -19 Med KlinIntensivmedNotfmed (2020)

[17] De Luca G,Cavalli G, Campochiaro C, Della- Torre E, Angelillo P ,Tomelleri A, et al. (16 june 2020). “ GM-CSF blockade with mavrilimumab in severe COVID-19 pneumonia and systemic hyperinflammation : $\mathrm{s}$ single centre,prospective cohort study" The Lancet Rheumatology.2 (8):e465e473. Doi:10.1016/s26659913(20)30170-3 PMC 3147227. PMID 21613310.

[18] Dong L, Hu S, Gao J (29 February 2020). "Discovering drugs to treat coronavirus disease2019 (COVID19)" . Drug Discoveries \& Therapeutics .14(1):58-60. Doi:10.5582/ddt.2020.01012. PMID 32147682 .

[19] Wang Y, Zhang D, Du G, Du R, Zhao J,Jin Y, et al (May 2020). "Remdesvir in adult with severe COVID-19: a randomised double blind placebo controlled, multicentric trial”. Lancet trail 395(10236): 15691578.

[20] Lu CC, Chen MY , Lee WS, Chang YL. Potential therapeutic agents against COVID-19: What we know so far. J Chin Med Assoc. 2020;83(6)

[21] Andersen PI, Lanevski A, Lysvand $\mathrm{H}$, Vitkauskiene A, Oksenych V, Bjoras M, et al.( April2020). "Discovery and development of safe in man broad spectrum antiviral agents".International Journal of Infectious Disease .93: 268-276

[22] “ Amid Ongoing COVID -19 Pandemic, Governor Cuomo Accepts Recommendation Of Army Corps Of Engineer for Four Temporary Hospital Sites in New York “ governor.ny.gov.22 March 2020.

[23] "RECOVERY Trial ". Retrieved 17 June 2020.

[24] QuiltyBJ,CliffordS.Effectivenessofai rportscreeningatdetectingtravellersinf ectedwithnovelcoronavirus(2019nCoV).Eurosurveillance 2020 Feb $6 ; 25(5)$

[25] Khatib, M.N., S. Gaidhane, M. Khatib, M. Ahmed, A. Gaidhane, and Z.Q. Syed. "SARS-CoV and SARSCoV-2: Similar Viruses with Different Trajectories." WutanHuatanJisuanJishu 16, no. 5 (2020): 544-48.

[26] Gaidhane, S., N. Khatib, Q.S. Zahiruddin, A. Gaidhane, S. Telrandhe, and P. Godhiwal. "Depression, Anxiety and Stress among the General Population in the Time of COVID-19 Lockdown: A Cross-Sectional Study Protocol." International Journal of Research in Pharmaceutical Sciences 11, no. Special Issue 1 (2020): 360-64. https://doi.org/10.26452/ijrps.v11iSP L1.2726.

[27] Nisargandha, M.A., and S. Dadaraoparwe. "Spread of Coronavirus Disease 2019 (COVID19) during the Lockdown in the 
Indian Population and Preventive Measures." International Journal of Research in Pharmaceutical Sciences 11, no. Special Issue 1 (2020): 32832.

https://doi.org/10.26452/ijrps.v11iSP L1.2721.

[28] Rajput, D.S. "Evolution, Ayurveda, Immunity, and Preventive Aspects for Emerging Infectious Diseases Such as COVID-19." International Journal of Research in Pharmaceutical Sciences 11, no. Special Issue 1 (2020): 86-93. https://doi.org/10.26452/ijrps.v11iSP L1.2227.

[29] Sharma, D. "Preventive Measures for COVID-19 Health Care Professionals." International Journal of Research in Pharmaceutical Sciences 11, no. Special Issue 1 (2020): 1307-12. https://doi.org/10.26452/ijrps.v11iSP L1.3626.

[30] Deshpande, A.M., and M.A. Deshpande. "Role of RasayanChurna in Outbreak of COVID-19 as Preventive and Curative Aspect." International Journal of Research in Pharmaceutical Sciences 11, no. Special Issue 1 (2020): 1208-12. https://doi.org/10.26452/ijrps.v11iSP L1.3594.

[31] Deshpande, M.A., and A.M. Deshpande. "Preventive Measures for COVID 19 through Dincharya and Rutucharya Mentioned in Ayurvedic Text." International Journal of Research in Pharmaceutical Sciences 11, no. Special Issue 1 (2020): 239-45. https://doi.org/10.26452/ijrps.v11iSP L1.2705.

[32] Khatod, S., A. Ikhar, P. Nikhade, and K. Khatod. "Preventive Measures for Dental Professionals during Worldwide Emergency COVID-19." International Journal of Research in Pharmaceutical Sciences 11, no.
Special Issue 1 (2020): 150-53. https://doi.org/10.26452/ijrps.v11iSP L1.2294.

[33] Dhole, P.D., V.K. Lohe, R.P. Kadu, S.C. Mohod, M. Meshram, and G.A. Thakare. "Post COVID-19 Protocol of Treatment, Radiologic Examination and Infection Control in Dentistry." International Journal of Research in Pharmaceutical Sciences 11, no. Special Issue 1 (2020): 138489.

https://doi.org/10.26452/ijrps.v11iSP L1.3664.

[34] Late, S.V., H. Keche, V.K. Chimurkar, and V. Anjankar. "Protocol for Handling and Disposal of the Dead Bodies in Covid-19." International Journal of Current Research and Review 13, no. 1 (2021): 7-9. https://doi.org/10.31782/IJCRR.2021 .13102 .

[35] Reche, A., R. Kolse, S. Gupta, A. Ingle, K.G. Chhabra, and G. Nimbulkar. "Therapeutic Options for COVID - 19: Pandemic - a Review." International Journal of Research in Pharmaceutical Sciences 11, no. Special Issue 1 (2020): 42024.

https://doi.org/10.26452/ijrps.v11iSP L1.2802.

[36] Thakre, P., W.M. Naqvi, T. Deshmukh, N. Ingole, and $\mathrm{S}$. Deshmukh. "Crucial Role of Physiotherapy in Treating Covid-19 Patients." International Journal of Research in Pharmaceutical Sciences 11, no. Special Issue 1 (2020): 96771.

https://doi.org/10.26452/ijrps.v11iSP L1.3300.

[37] Darwate, T., and S. Hiware. "Concept of Rasayana Therapy in Covid 19." International Journal of Research in Pharmaceutical Sciences 11, no. Special Issue 1 (2020): 85761. 
https://doi.org/10.26452/ijrps.v11iSP L1.3093.

[38] Deogade, M.S. "Agnihotra (Homa)an Ayurveda Therapy in the Prevention and Control of Covid19." International Journal of Research in Pharmaceutical Sciences 11, no. Special Issue 1 (2020): 3049.

https://doi.org/10.26452/ijrps.v11iSP L1.2717.

[39] Jameel, P.Z., and A.M. Taksande. "COVID-19: A Review of Drugs and Therapies for Children." Sri Lanka Journal of Child Health 49, no. 3 (2020): 210-17. https://doi.org/10.4038/sljch.v49i3.9 136.

[40] Joseph, M.B., S. Pohekar, A. Raut, and M. Patil. "The Palliative Care and Covid-19 Pandemic." International Journal of Research in Pharmaceutical Sciences 11, no. Special Issue 1 (2020): 618-22. https://doi.org/10.26452/ijrps.v11iSP L1.2861.

[41] Afaque, S.Y. "Association and Treatment of Diabetes in Patients Affected by COVID-19." International Journal of Research in Pharmaceutical Sciences 11, no. Special Issue 1 (2020): 1198-1201. https://doi.org/10.26452/ijrps.v11iSP L1.3591.

[42] Agrawal, A., P. Fulzele, K. Deo, Z.S. Quazi, and A. Daryapurkar. "Engineered Nano-in-Micro Drug Delivery Scheme against Sars-Cov2: A Hypothesis." European Journal of Molecular and Clinical Medicine 7, no. 7 (2020): 1892-1901.

[43] Dhole, P.D., V.K. Lohe, R.P. Kadu, S.C. Mohod, M. Meshram, and G.A. Thakare. "Post COVID-19 Protocol of Treatment, Radiologic Examination and Infection Control in Dentistry." International Journal of Research in Pharmaceutical Sciences 11, no. Special Issue 1 (2020): 1384-
89.

https://doi.org/10.26452/ijrps.v11iSP L1.3664.

[44] Gulhane, A., and S. Hiware. "Nutritional Recommendation for COVID-19." International Journal of Research in Pharmaceutical Sciences 11, no. Special Issue 1 (2020): 75357. https://doi.org/10.26452/ijrps.v11iSP L1.3078. 